\title{
4,8-Sphingadienine and 4-hydroxy-8-sphingenine activate ceramide production in the skin
}

\author{
Yoshiyuki Shirakura', Kanako Kikuchi ${ }^{1}$ Kenji Matsumura', Katsuyuki Mukai', Susumu Mitsutake² \\ and Yasuyuki Igarashi ${ }^{2^{*}}$
}

\begin{abstract}
Background: Ingestion of glucosylceramide improves transepidermal water loss (TEWL) from the skin, but the underlying mechanism by which a small amount of dietary glucosylceramide can vastly improve skin conditions remains unclear. In a previous report, glucosylceramides were shown to be digested to sphingoids, which were shown to be absorbed through the intestinal epithelium. Based on these observations, we hypothesized that sphingoids are the key molecules facilitating endogenous ceramide production. In this study, we assessed the effect of 4,8-sphingadienine (d18:2) and 4-hydroxy-8-sphingenine (t18:1), derived from konjac glucosylceramide, on stimulating ceramide production.

Methods: Konjac glucosylceramide acidolysis was performed using hydrochloric acid; the resulting d18:2 and t18:1 were fractionated by column chromatography. Real-time quantitative RT-PCR was performed to assess the effect of d18:2 and t18:1 on gene expression in normal human epidermal keratinocytes, while their effect on the nuclear receptor, peroxisome proliferator-activated receptor (PPAR)y, was measured using a receptor-cofactor assay system. The effect of d18:2 and t18:1 on stimulating ceramide production was evaluated using HPTLC analysis in a 3dimensional human skin model.

Results: We noted the upregulation of genes related to de novo ceramide synthesis as well as of those encoding the elongases of very long-chain fatty acids by d18:2 and t18:1, but not by glucosylceramide and 4-sphingenine. Both these sphingoids also facilitated the expression of PPAR $\beta / \delta$ and PPARY; moreover, they also demonstrated ligand activity for PPARY. These results indicated that d18:2 and t18:1 promote the differentiation of keratinocytes. Analysis of the lipids within the 3-dimensional human skin model indicated that treatment with d18:2 and t18:1 not only upregulated gene expression but also increased ceramide production.
\end{abstract}

Conclusions: The sphingoids d18:2 and t18:1 activated genes related to de novo ceramide synthesis and increased ceramide production, whereas glucosylceramide and 4-sphingenine could not. These results suggest that the effect of dietary glucosylceramides on the skin is mediated by d18:2 and t18:1.

Keywords: 4,8-sphingadienine, 4-hydroxy-8-sphingenine, Ceramide synthesis

\section{Background}

Ceramide is a sphingolipid that is composed of a long-chain sphingoid base with 2-amide groups linked to a fatty acid $[1,2]$. Because of the various combinations of diverse sphingoids and fatty acids, ceramide is a generic name used for more than 10 such molecular species in humans [3]. Ceramides are found not only in animals but also in plants and fungi. Each ceramide has characteristic structures. Ceramides

\footnotetext{
* Correspondence: yigarash@pharm.hokudai.ac.jp

${ }^{2}$ The Graduate School of Life Science, Faculty of Advanced Life Science, Hokkaido University, Nishi 11, Kita 21, Kita-ku, Sapporo 001-0021, Japan
} Full list of author information is available at the end of the article derived from plants are mostly glucosylated (glucosylceramide), while the sphingoid residue mainly has a double bond between C8 and C9 [4]. Fig. 1 shows the typical sphingoid structures derived from animals and from higher plants. Sphingoid structures from fungi share features with those from plants, but, in addition, are methylated at C9 $[5,6]$.

Animal ceramides are present not only in the plasma membranes of cells but also in the extracellular matrix of the stratum corneum, where the ceramide content among the intracellular lipids of the stratum corneum reaches approximately $50 \%$. Ceramides and their metabolites form
C Biomed Central

(c) 2012 Shirakura et al.; licensee BioMed Central Ltd. This is an Open Access article distributed under the terms of the Creative Commons Attribution License (http://creativecommons.org/licenses/by/2.0), which permits unrestricted use, distribution, and reproduction in any medium, provided the original work is properly cited. 


\section{<Animal type $>\quad<$ Higher plant type $>$}

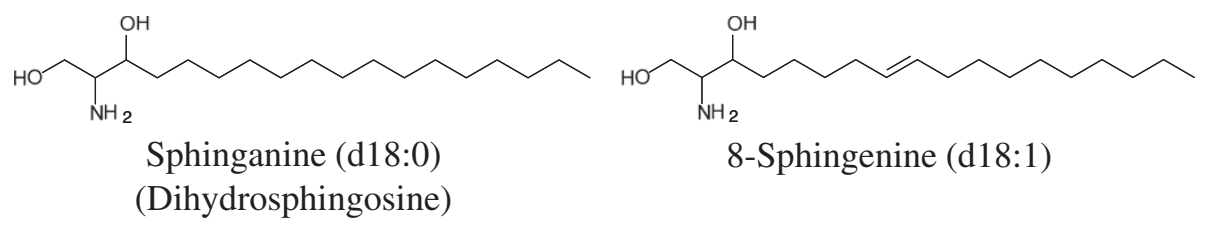<smiles>CCCCCCCCCCCCC/C=C/C(O)C(N)CO</smiles>
(Sphingosine)<smiles>CCCCCCCCCCCCCCC(O)C(O)C(N)CO</smiles>

4-Hydroxysphinganine (t18:0) (Phytosphingosine)<smiles>CCCCCCCCC/C=C/CC/C=C/C(O)C(N)CO</smiles>

4,8-Sphingadienine (d18:2)<smiles>CCCCCCCCC/C=C/CCCC(O)C(O)C(N)CO</smiles>

4-Hydroxy-8-sphinganine (t18:1)

Figure 1 Structure of animal- and higher plant-type sphingoids. The consensus structure of sphingoids from animals and higher plants. The higher plant-type is characterized by a double bond between C8 and C9.

the multilamellar permeability barrier [7]; thus, a reduction in ceramides causes some skin disorders such as atopic dermatitis [8]. Ceramides are also important in signal transduction. For example, phosphorylated ceramide and its metabolites act as an intracellular signaling factor for inducing apoptosis [9].

Uchiyama et al. reported that dietary glucosylceramides derived from the konjac tuber reduce transepidermal water loss (TEWL) from the skin [10]. The mechanism by which a small amount of dietary glucosylceramides can improve skin conditions remains unclear. In this study, we attempted to assess the relationship between dietary glucosylceramides and ceramide production in the skin.

A previous study reported that glucosylceramides are digested to sphingoids, which are then absorbed though the intestinal epithelium [11]. Under the hypothesis that skin condition improvement may be mediated by the signaling function of sphingoids, we assessed the ability of sphingoids to induce gene expression in normal human epidermal keratinocytes (NHEK), as well as their nuclear receptor binding activities. The effect of ceramide production was evaluated with the TEST SKIN ${ }^{\mathrm{TM}}$ LSE-high, a 3-dimensional cultured human skin model.

\section{Methods}

\section{Materials}

Glucosylceramide derived from konjac tuber was purchased from Nagara Science (Gifu, Japan). 4-Sphingenine and PCR primers were purchased from Sigma Aldrich Japan (Tokyo, Japan). Isogen was purchased from Nippon Gene (Tokyo, Japan). Reverse transcriptase, SYBR-Premix Ex-taq were purchased from TaKaRa Bio Inc (Shiga, Japan). CCK-8 was purchased from DOJINDO LABORATORIES (Kumamoto, Japan). NHEK and the culture medium, Humedia KB2, including the additive agents, were purchased from Kurabo (Osaka, Japan). A receptor-cofactor assay system (RCAS) kit was purchased from Fujikura Kasei (Tokyo, Japan). TEST SKIN ${ }^{\mathrm{TM}}$ LSE-high was purchased from Toyobo (Osaka, Japan).

\section{Preparation of sphingoid bases from glucosylceramide} 4,8-Sphingadienine (d18:2) and 4-hydroxy-8-sphingenine (t18:1) were prepared by acidolysis of konjac glucosylceramide and column chromatography. Glucosylceramide (1.5 g) was incubated with $400 \mathrm{~mL}$ of methanol containing $1 \mathrm{~N} \mathrm{HCl}$ at $70{ }^{\circ} \mathrm{C}$ for $18 \mathrm{~h}$, which was followed by extraction with $100 \mathrm{~mL}$ hexane twice, to eliminate methyl esters of fatty acids. Sodium hydroxide solution $(4 \mathrm{~N})$ was used to neutralize the water phase. Chloroform and methanol were added to the mixture to attain a 1:1:1 (v:v:v) ratio of chloroform:methanol:water, which was followed by vigorous agitation. The chloroform phase was collected and concentrated in vacuo. The resulting residue was dissolved in chloroform and loaded onto a Chromatorex NH-DM1020 column (30 mm × 170 mm; Fuji Silysia 
Chemical, Kasugai, Japan) for column chromatography. Stepwise elution was performed with chloroform/methanol at ratios of 100:0 $(150 \mathrm{~mL}), 90: 10(150 \mathrm{~mL}), 70: 30$ $(150 \mathrm{~mL})$, and 50:50 $(300 \mathrm{~mL})$. The eluents collected were analyzed by HPLC after solvent evaporation.

\section{HPLC analysis of sphingoid bases}

The sphingoids prepared were analyzed by HPLC by using a Supersphere 100 RP-18(e) column (Merck, Japan), at $40^{\circ} \mathrm{C}$. Isocratic elution was performed using methanol/distilled water/ammonium acetate in a ratio of 95:5:0.1 ( $/ \mathrm{v} / \mathrm{w})$ as mobile phase. This was followed by detection using an evaporative light scattering detector (ELSD; Alltech, Deerfield, USA).

\section{Cell culture}

NHEK was cultured using Humedia-KB2 medium with growth enhancers, viz., epidermal growth factor, insulin, hydrocortisone, bovine pituitary extract, and an antimicrobial agent. NHEK cells $(10,000)$ were seeded in 24-well plates and cultured for $4 \mathrm{~d}$; medium was exchanged every $2 \mathrm{~d}$. On the fifth day, the medium was replaced with new medium supplemented with test materials, at the indicated concentrations: 4-sphingenine $(5 \mu \mathrm{g} / \mathrm{mL}, 16.7 \mu \mathrm{M})$; 4,8-sphingadienine ( $5 \mu \mathrm{g} / \mathrm{mL}, 16.8 \mu \mathrm{M})$; 4-hydroxy-8-sphingenine $(5 \mu \mathrm{g} / \mathrm{mL}, 15.8 \mu \mathrm{M})$; and glucosylceramide $(13 \mu \mathrm{g} / \mathrm{mL}, 16.9 \mu \mathrm{M})$. After a $24 \mathrm{~h}$ cultivation, cells were used to assess gene expression.

TEST SKIN ${ }^{\text {TM }}$ LSE-high was cultured in the medium supplied by the manufacturer, and cultivation was performed according to the instruction manual. The medium was adjusted at the indicated concentration, 4,8-sphingadienine $(2.5 \mu \mathrm{g} / \mathrm{ml}, 8.4 \mu \mathrm{M}$ and $10 \mu \mathrm{g} / \mathrm{ml}, 33.4 \mu \mathrm{M})$, 4-hydroxy-8-sphingenine $(2.5 \mu \mathrm{g} / \mathrm{ml}, \quad 7.9 \mu \mathrm{M}$ and $10 \mu \mathrm{g} / \mathrm{ml}, 31.7 \mu \mathrm{M})$ and glucosylceramide $(26 \mu \mathrm{g} / \mathrm{ml}$, $33.9 \mu \mathrm{M})$, and the medium was exchanged $48 \mathrm{~h}$ after the start of cultivation. By $72 \mathrm{~h}$ after the start of culturing, the topmost keratinocytes were removed and analyzed.

\section{RNA extraction and real-time PCR}

Total RNA was isolated from NHEK cell lysates $24 \mathrm{~h}$ after adding test samples, using Isogen reagent according to the manufacturer's protocol. cDNA was synthesized from total RNA by using a PrimerScript RT reagent kit with an oligodT primer. Real-time quantitative RT-PCR analysis was performed using SYBR-Premix Ex-taq and automated sequence detection systems (StepOne; Applied Biosystems Japan Ltd, Tokyo, Japan). PCR cycling was performed using 2 conditions. Condition 1 involved 40 cycles, each consisting of $15 \mathrm{~s}$ at $95^{\circ} \mathrm{C}$ and $1 \mathrm{~min}$ at $60^{\circ} \mathrm{C}$, and was used for serine palmitoyltransferase long chain (SPTLC) 2, dihydroceramide desaturase (DEGS)-1, ceramide synthase (CERS) 2-6, glucosylceramide synthase (GCS), $\beta$-glucocerebrosidase ( $\beta$-GCS), the elongases of very long-chain fatty acids (ELOVL)-1, 4-7, peroxisome proliferator-activated receptor (PPAR) $\beta / \delta, \gamma$ amplification. Condition 2 involved 40 cycles, each consisting of $15 \mathrm{~s}$ at $95^{\circ} \mathrm{C}, 15 \mathrm{~s}$ at $60^{\circ} \mathrm{C}$, followed by $1 \mathrm{~min}$ at $72^{\circ} \mathrm{C}$, and was used for sphingomyelin synthase (SMS)-1,2 and sphingomyelinase (SMase). The sequences of the primers are shown in Table 1. The sequences of the primers were designed by the references [12-21], software and web site.

\section{Nuclear receptor-binding assays}

Nuclear receptor-binding assays were performed using an RCAS kit according to the manufacturer's protocol. All the results were normalized to the negative control (ETOH). GW1929, included in the kit, was used as the positive control.

\section{Ceramide extraction}

The topmost keratinocyte layer was removed from the cultured TEST SKIN ${ }^{\mathrm{TM}}$ LSE-high and cut into small pieces. These pieces were soaked in $2 \mathrm{~mL}$ of chloroform/methanol $(1: 2, \mathrm{v} / \mathrm{v})$ and were left to stand at room temperature for $1 \mathrm{~h}$ to extract the ceramides. The liquid phase was transferred to a collection tube, and the residual keratinocytes were extracted in the same manner twice more, using chloroform/methanol/distilled water (1:2:0.5, v/v) and chloroform, and all extracts were pooled. To this was added $600 \mu \mathrm{L}$ of $2.5 \% \mathrm{KCl}$ and $6 \mathrm{~mL}$ of distilled water; the samples were mixed well, followed by centrifugation at $900 \times g$ at room temperature for $5 \mathrm{~min}$. The lower phase was transferred to a new tube, and the upper layer was re-extracted with $4 \mathrm{~mL}$ of chloroform by vortexing the tube for $30 \mathrm{~s}$, followed by a similar centrifugation step. The extract was dried at $50^{\circ} \mathrm{C}$ under a stream of nitrogen gas. The residue was dissolved in $100 \mu \mathrm{L}$ chloroform/methanol (2:1, v:v) and was stored in a screw-top bottle at $-20^{\circ} \mathrm{C}$ until use [22].

\section{HPTLC analysis of extracted lipids}

The extracted lipids were analyzed by means of highperformance thin-layer chromatography (HPTLC) on an HPTLC plate (Merck, Tokyo, Japan); the following mobile phases and distances were used, in this order:

1. Chloroform, for $15 \mathrm{~mm}$

2. Chloroform/acetone/methanol (76:8:16, v:v:v), for $10 \mathrm{~mm}$

3. Chloroform/hexylacetate/acetone/methanol (86:1:10:4, v:v:v:v), for $70 \mathrm{~mm}$

4. Chloroform/acetone/methanol (76:4:20, v:v:v), for $20 \mathrm{~mm}$

5. Chloroform/diethylether/hexylacetate/ethylacetate/ acetone/methanol (72:4:1:4:16:4, v:v:v:v:v:v), for $75 \mathrm{~mm}$

6. Hexane/diethylether/ethylacetate (80:16:4, v:v:v), for $90 \mathrm{~mm}$ 
Table 1 Primers for quantitative RT-PCR

\begin{tabular}{|c|c|c|c|}
\hline Gene & Primer sequence (Forward) & Primer sequence (Reverse) & Reference \\
\hline SPTLC2 & CCAGACTGTCAGGAGCAACCATTA & CGTGTCCGAGGCTGACCATA & \\
\hline CerS2 & CCGATTACCTGCTGGAGTCAG & GGCGAAGACGATGAAGATGTTG & [12] \\
\hline CerS3 & ACATTCCACAAGGCAACCATTG & СTCTTGATTCCGCCGACTCC & [12] \\
\hline CerS4 & CTTCGTGGCGGTCATCCTG & TGTAACAGCAGCACCAGAGAG & [12] \\
\hline CerS5 & GCCATCGGAATCAGGAC & GCCAGCACTGTCGGATGT & [12] \\
\hline CerS6 & GGGATCTTAGCCTGGTTCTGG & GCCTCCTCCGTGTTCTTCAG & [12] \\
\hline DEGS-1 & GCGTTTGGCAGTTGCATTAA & CATTGTGGGCAATCTCATGAA & designed by Primer Express \\
\hline SMS-1 & GCCAGGACTTGATCAACCTAACC & CCATTGGCATGGCCGTTCTTG & [13] \\
\hline SMS-2 & CACCCAGTGGCTGTTTCTGA & TGCATTCCAGGCACAGGTAGA & [13] \\
\hline aSMase & TGGCTCTATGAAGCGATGGC & TTGAGAGAGATGAGGCGGAGAC & [14] \\
\hline$\beta-G C S$ & GCTAGGCTCCTGGGATCGAG & GTTCAGGGCAAGGTTCCAGTC & [15] \\
\hline GCS & GTTCGTCCTCTTCTTGGTGC & AGAAGAGAGACACCTGGGAGC & [16] \\
\hline ELOVL-1 & ATTCTCCTGACCTACGTGTACTT & TTCCGATTAGCCATGATGCGA & Primer Bank \\
\hline ELOVL-4 & CATGTGTATCATCACTGTACG & AAAGGAATTCAACTGGGCTC & [17] \\
\hline ELOVL-5 & TAACAGGAGTATGGGAAGGCA & ACCAGAGGACACGGATAATCTT & Primer Bank \\
\hline ELOVL-6 & TGCTGCCTITATATTCGGTGG & CCTCAGTTCAAACTITGCTCGTT & Primer Bank \\
\hline ELOVL-7 & TTCCATCATACCATCATGCC & CCCAATGCAGAAAGTCCATA & [18] \\
\hline PPAR $/ \delta$ & ACAGCATGCACTTCCTTCCA & TCACATGCATGAACACCGTA & [19] \\
\hline PPARY & ATTCTGGCCCACCAACTTTG & TCCATTACGGAGAGATCCACG & [20] \\
\hline GAPDH & TGCACCACCAACTGCTTAGC & GGCATGGACTGTGGTCATGAG & [21] \\
\hline
\end{tabular}

Primer sequences used in real-time quantitative RT-PCR in this study. All primers were used with SYBR-Green and their specificities checked using the melting curve method $\left(60-95^{\circ} \mathrm{C}\right)$.

After the solvent had evaporated, the HPTLC plate was sprayed with acetate $/ \mathrm{H}_{2} \mathrm{PO}_{4} / \mathrm{H}_{3} \mathrm{PO}_{4} / 0.5 \% \mathrm{CuSO} 4$ solution (5:1:1:95, v:v:v:v) and heated to $160{ }^{\circ} \mathrm{C}$ to visualize the separated lipids. The colored plate was immediately scanned using a densitometer.

\section{Statistical analysis}

All the data are presented as mean \pm SD values. Statistical significance was determined using Student's $t$-test; $p<0.05$ was considered to be statistically significant.

\section{Results}

\section{Ceramide de novo synthesis-related gene expression}

Purified glucosylceramide ( $\geq 99 \%$ ) from konjac tuber was digested to sphingoids in the presence of hydrochloric acid. Table 2 shows the composition of sphingoids analyzed by GC-MS. The major sphingoid moieties of konjac glucosylceramide are 4,8-sphingadienine and 4-hydroxy-8-sphingenine. We examined the effects of the major sphingoids derived from konjac glucosylceramide on the expression of genes related to de novo synthesis of ceramide by using real-time quantitative PCR.

First, we checked the toxicity of the sphingoids to the NHEK cells. CCK-8 was used to measure the cell viability after $24 \mathrm{~h}$ exposure of sphingoids. There were no differences between cells after sphingoids and vehicle treatment.

Then we used the assessed the expression of these genes in d18:2 and t18:1-treated NHEK cells. As shown in Fig. 2A, the expression of SPTLC2, CerS3, DEGS-1, $S M S-1$, aSMase, and GCS increased by 1.1-fold, 2.4-fold, 1.4-fold, 1.2-fold, 2.2-fold, and 2.6-fold, respectively, following exposure of the cells to $5 \mu \mathrm{g} / \mathrm{mL}$ d18:2. The expression of CerS3, aSMase, and GCS increased by 2.5 -fold, 4.7 -fold, and 1.3-fold, respectively, in the presence of $5 \mu \mathrm{g} / \mathrm{mL} \mathrm{t} 18: 1$.

Second, we tested the expression of ELOVL-1, ELOVL-4, ELOVL-5, ELOVL-6, and ELOVL-7. As shown in Fig. 2B, the expression of ELOVL-1, ELOVL-4, and ELOVL-7

Table 2 Sphingoid composition of konjac glucosylceramide

\begin{tabular}{lll}
\hline Sphigoid base & double bond & composition(\%) \\
\hline $\mathrm{t} 18: 0$ & - & 1.4 \\
$\mathrm{t} 18: 1$ & $\mathrm{C} 8-\mathrm{C} 9$ & 40.2 \\
$\mathrm{~d} 18: 1$ & $\mathrm{C} 8-\mathrm{C} 9$ & 3.8 \\
$\mathrm{~d} 18: 1$ & $\mathrm{C} 4-\mathrm{C} 5$ & 0.6 \\
d18:2 & C4-C5,C8-C9 & 54.0
\end{tabular}

Sphingoid bases are presented in abbreviated style. d18:0 has 2 hydroxyl groups and 18 carbons, without any double bonds, whereas t18:1 has 3 hydroxyl groups, and 18 carbons, with 1 double bond. 


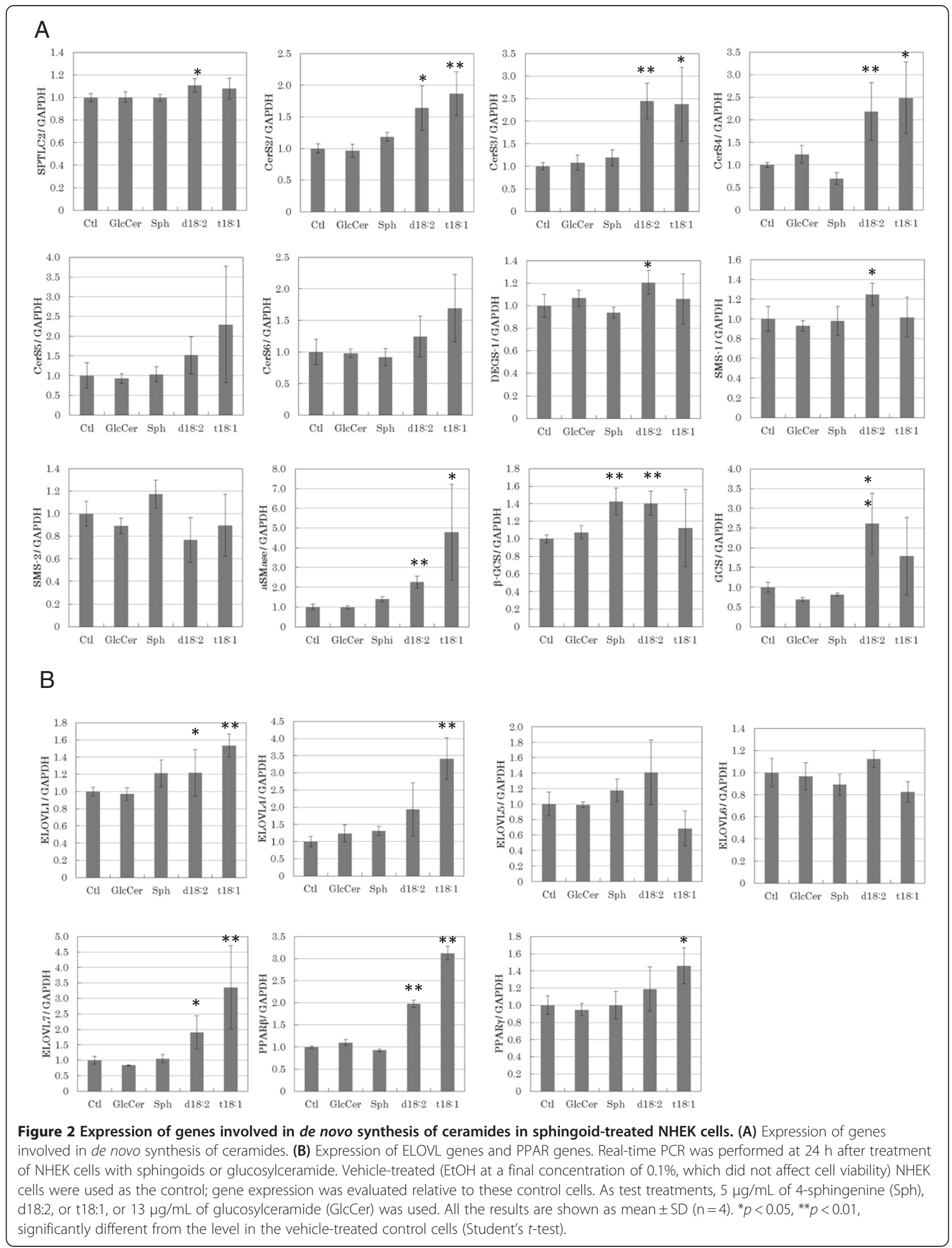


increased by 1.2-fold, 1.9-fold, and 1.9-fold, respectively, in the presence of $5 \mu \mathrm{g} / \mathrm{mL}$ d18:2. Moreover, in the presence of $5 \mu \mathrm{g} / \mathrm{mL}$ t18:1, the expression of these 3 genes increased by 1.5 -fold, 3.4-fold, and 3.3-fold, respectively.

We also tested the expression of $P P A R \beta / \delta$, and $P P A R \gamma$, which are known to promote the differentiation of keratinocytes. As shown in Fig. 2B, expression of $P P A R \beta / \delta$ in the presence of $5 \mu \mathrm{g} / \mathrm{mL} \mathrm{d} 18: 2$ or t18:1 increased by 2.0-fold and 3.0-fold, respectively. PPAR expression increased by 1.4 -fold in the presence of $5 \mu \mathrm{g} / \mathrm{mL}$ t18:1. In contrast, neither glucosylceramide nor 4-sphingenine had any marked effects on the expression of these genes.

\section{PPARy ligand}

The ability of d18:2 and t18:1 to act as ligands of PPAR $\gamma$ was assessed using nuclear receptor assays. As shown in Fig. 3, no binding of glucosylceramide to PPAR $\gamma$ was observed. In contrast, d18:2 and t18:1 showed efficient binding to PPAR $\gamma$. These results suggested that d18:2 and t18:1 are ligands of PPAR $\gamma$ and thus participate in positive feedback regulation of PPAR $\gamma$ activity, including induction of differentiation in keratinocytes.

\section{Ceramide sysnthesis in 3-dimensional human skin model}

To assess the upregulation of ceramide production by $\mathrm{d} 18: 2$ and $\mathrm{t} 18: 1$, we used a reconstituted human skin model, TEST SKIN ${ }^{\mathrm{TM}}$ LSE-high. As shown in Fig. 4, we identified 7 ceramide spots [23]; d18:2 treatments of the skin model increased the intensities of ceramide III (NP) spots, while t18:1 treatments increased the intensities of ceramide I (EOS), II (NS), and III (NP), compared to vehicle (ethanol) and glucosylceramide treatments. These results are summarized in Table 3, in which the digitized intensities of the spots are recorded. These results indicate that $\mathrm{d} 18: 2$ and $\mathrm{t} 18: 1$ induce ceramide production in a human skin model.

\section{Discussion}

Although previous reports have demonstrated that dietary glucosylceramide can decrease TEWL from human skin [24], the mechanism was unclear. Ueda et al. reported that orally administrated ceramide was distributed to the dermis after intestinal absorption, followed by transfer from the dermis to the epidermis [25]. Ishikawa et al. also showed that dietary glucosylceramide was degraded into sphingoids, which were absorbed through the intestinal epithelial cells of rats and were subsequently also found in the lymph fluid in these rats [11]. Another study showed that 4-hydroxysphinganine could activate the PPARs [26] that are the key regulators of keratinocyte differentiation [27].

Keratinocyte differentiation is closely related to internal ceramide synthesis [28]. It is unlikely that orally ingested glucosylceramide would specifically localize to the skin because the amount of ingested glucosylceramide is simply too little to enhance ceramide levels in the skin. We hypothesized that sphingoids are the most likely effectors of ceramide production in the skin. In the present study, we used d18:2 and t18:1 as candidates because they were the major constituents of konjac glucosylceramide, as shown in Table 2. Daily oral intake of $1.8 \mathrm{mg}$ konjac glucosylceramide for 28 days had improved transepidermal water loss (TEWL) of the skin| in a human trial [10]. Previous report [26] showed that phytoceramide activated PPARs at the concentration of above $10 \mu \mathrm{M}$. According this report, it was $10 \mu \mathrm{M}$ that we

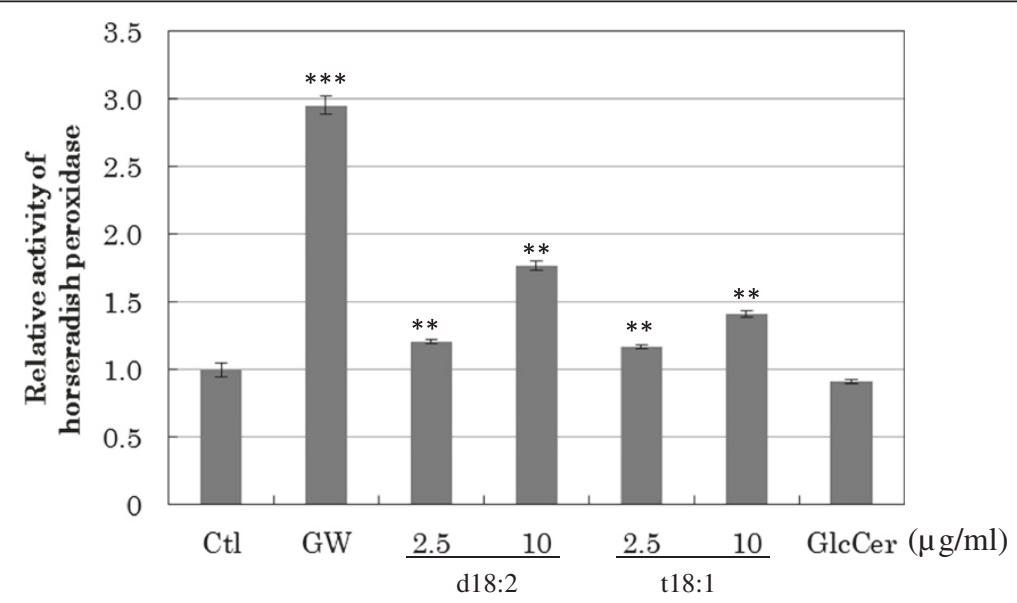

Figure 3 Activation of PPARy by sphingoids. The ability of 2.5 and $10 \mu \mathrm{g} / \mathrm{mL}$ of sphingoids or $26 \mu \mathrm{g} / \mathrm{mL}$ glucosylceramide to bind and activate PPARy was measured using a receptor cofactor assay system. As positive control, 8 mM of GW1929 was used. Horseradish peroxidase activity was normalized to the absorption at $450 \mathrm{~nm}$. All the results are shown as mean \pm SD values $(n=3) .{ }^{* *} p<0.01,{ }^{* * *} p<0.001$, significantly different from the levels in vehicle-treated control cells. 


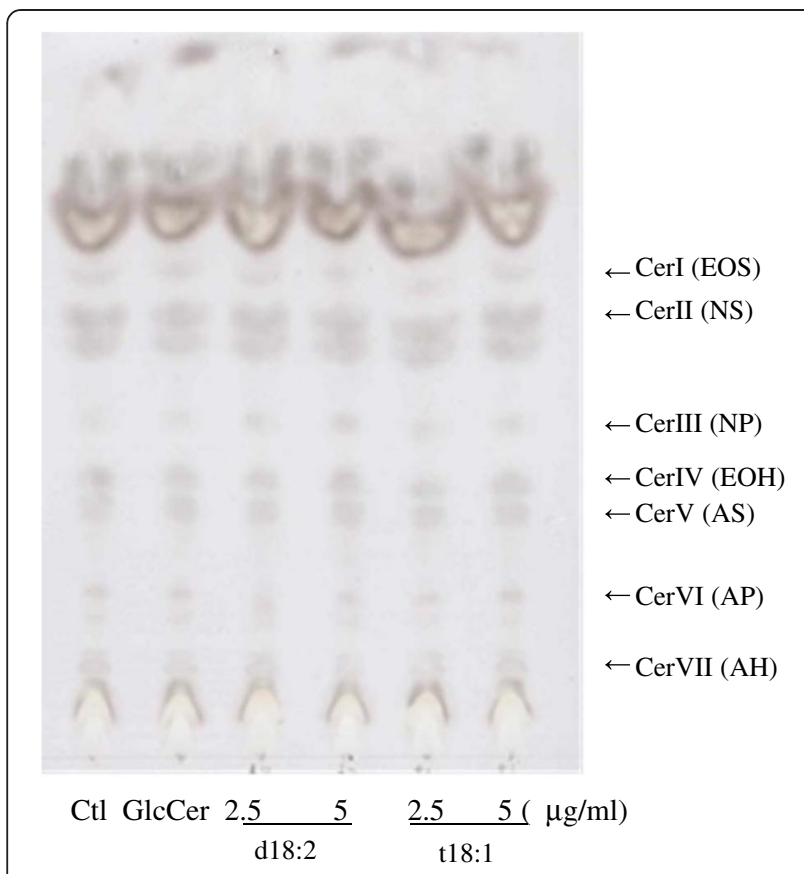

Figure 4 HPTLC of ceramides extracted from a 3-dimensional human skin model treated with sphingoids. Two wells containing 3-dimensional human skin model samples were pooled per sample. The weight of the keratinocyte layer was measured soon after the removal of this layer from the model; the values for all samples were subsequently adjusted to this weight. The same amount of lipids extracted from the keratinocyte layer of all samples was loaded onto the HPTLC plate. To visualize the ceramides, the HPTLC plate was treated with acetate $/ \mathrm{H}_{2} \mathrm{PO}_{4} / \mathrm{H}_{3} \mathrm{PO}_{4} / 0.5 \% \mathrm{CuSO}$ solution and heated. Abbreviations of Cer I to VII represent Ceramide I to VII, these are classical names base on rate of flow in TLC. Recent names based on the structure, the combination of fatty acid and sphingoids, were shown in the parenthesis. A = a-hydroxy fatty acid, EO=Esterified $\omega$ hydroxy fatty acid, $\mathrm{N}=$ Non-hydroxy fatty acid, $\mathrm{P}=$ Phytosphingosine, $\mathrm{S}=$ Sphingosine, $\mathrm{H}=6$-Hydroxy sphingosine.

assumed the enough concentration for the activation of ceramide de novo synthesis. In this study (in vitro), the concentration was adopted from $8.4(2.5 \mu \mathrm{g} / \mathrm{ml})$ to 33.4. $\mu \mathrm{M}(10 \mu \mathrm{g} / \mathrm{ml})$ for sphingoids and glucosylceramide. As a result, the upregulation of ceramide de novo synthesis, the activation of PPAR $\gamma$ and the induction of ceramides in 3-dimensional human skin model have been cofirmed.
Real-time quantitative RT-PCR was performed using NHEK cells that had been treated with sphingoids and glucosylceramide. We tested the effects of $\mathrm{d} 18: 2$ and t18:1 on the expression of genes related to de novo ceramide synthesis, including SPTLC2, DEGS-1, and CerS2-b [29,30], the ELOVL family, and PPARs. Glucosylceramide and 4-sphingenine had no noticeable effects on the expression of these genes; in contrast, $\mathrm{d} 18: 2$ and t18:1 could activate the expression of these genes. Among the products of the genes activated, CerS3 catalyzes the production of epidermal ceramides [7], and CerS2 regulates ELOVL-1-mediated synthesis of C22-CoA from C18 via $\mathrm{C} 20$, which is an essential step in the production of $\mathrm{C} 24$ ceramide [31]. Our data therefore indicated the possibility of induction of keratinocyte differentiation and ceramide production as a result of treatment with $\mathrm{d} 18: 2$ and $\mathrm{t} 18: 1$.

We next attempted to assess the activatory effects of $\mathrm{d} 18: 2$ and $\mathrm{t} 18: 1$ on PPAR $\gamma$ by using in vitro binding assays. We found that d18:2 and t18:1 could activate PPAR $\gamma$, whilst glucosylceramide could not. The results of our gene expression studies and binding assays indicated that $\mathrm{d} 18: 2$ and t18:1 promote the differentiation of keratinocytes and stimulate endogenous ceramide production.

When we investigated the effects of these compounds on TEST SKIN ${ }^{\mathrm{TM}}$ LSE-high, we observed that ceramides I, II, and III were induced by $\mathrm{d} 18: 2$ and $\mathrm{t} 18: 1$ treatment. This indicated that $\mathrm{d} 18: 2$ and t18:1 promoted not only the induction of gene expression but also the production of ceramides in human skin.

As mentioned earlier, various reactions were induced by $\mathrm{d} 18: 2$ and t18:1 but not by 4 -sphingenine. The major structural difference between the active sphingoids and 4-sphingenine is a $\mathrm{C} 8-\mathrm{C} 9$ double bond. A previous report demonstrated that 4-hydroxysphinganine (t18:0) could act as a ligand for PPARs [26,32]. This is the first report that $\mathrm{t} 18: 1$ and $\mathrm{d} 18: 2$ are the agonists for PPAR $\gamma$. As 4-sphingenine (d18:1) did not act as PPAR $\gamma$ agonist, some functional molecular structure, for example 4-hydroxy (t18:0 and t18:1) or C8 double bond (t18:1 and $\mathrm{d} 18: 2$ ), might be needed to activate PPARs.

Nine species of sphingoids are commonly found in plants [33], and many sources of glucosylceramide other than konjac tuber exist, e.g., rice bran, corn, apple, and

Table 3 Levels of ceramide in a 3-dimensional human skin model treated with sphingoids

\begin{tabular}{lllllll}
\hline & Ctl & GlcCer & $\mathbf{d} \mathbf{1 8 : 2} \mathbf{2 . 5} \mathbf{\mu g} / \mathbf{m L}$ & $\mathbf{d} \mathbf{1 8 : 2} \mathbf{5} \boldsymbol{\mu \mathbf { g } / \mathbf { m L }}$ & $\mathbf{t 1 8 : 1} \mathbf{2 . 5} \boldsymbol{\mu \mathbf { g } / \mathbf { m L }}$ & $\mathbf{t 1 8 : 1 \mathbf { 5 }} \boldsymbol{\mu \mathbf { g } / \mathbf { m L }}$ \\
\hline Cer I (EOS) & 1.00 & 0.82 & 0.87 & 0.98 & 1.10 & 1.27 \\
Cer II (NS) & 1.00 & 0.78 & 0.92 & 0.91 & 1.18 & 1.20 \\
Cer III (NP) & 1.00 & 1.24 & 1.19 & 1.90 & 1.65 & 1.83 \\
\hline
\end{tabular}

A 3-dimensional human skin model, TEST SKIN ${ }^{\mathrm{TM}}$, was cultured in medium containing sphingoids or glucosylceramide for $72 \mathrm{~h}$. Ceramides were then extracted from the topmost keratinocyte layer and analyzed by HPTLC. The levels of ceramides were assessed by densitometry; results were evaluated relative to the densities in vehicle-treated control samples. 
sugar beet pulp. These glucosylceramides also contain $\mathrm{d} 18: 2$ and t18:1, but these sphingoids are not as abundant as in konjac, suggesting that konjac is the most effective source of material for improving skin ceramide production.

Water retention of the skin decreases because of aging, UV exposure, and diseases such as atopic dermatitis [7]. These factors cause the depletion of skin ceramides and a reduction in hyaluronic acid, and lead to inflammation and wrinkling of the skin. In contrast, dietary glucosylceramides can improve the condition of the skin $[34,35]$. Because the amount of glucosylceramide ingestion is so limited, it is believed that improvement of the skin is not due to the direct localization of glucosylceramide to the skin. In this study, we have shown that at least part of the mechanism involves a triggering of the ceramide synthesis pathway by $\mathrm{d} 18: 2$ and t18:1. Further studies may help elucidate the complete mechanism underlying efficient improvement of skin conditions through dietary glucosylceramides, thereby contributing to human health and wellbeing.

\section{Competing interests}

The authors declare that they have no competing interests.

\section{Authors' contributions}

YS participated in the design of the study, carried out analysis and interpretation of data and drated the manuscript. KK and Kenji M carried out processing of glucosylceramide. Katsuyuki M participated in the design of the study, contributed to the interpretation of data and revised the manuscript. SM and YI participated in the design of the study and contributed to the interpretation of data. All authors read and approved the final manuscript.

\section{Author details}

${ }^{1}$ R\&D Center, UNITIKA Ltd, 23 Kozakura, Uji-shi, Kyoto 611-0021, Japan. ${ }^{2}$ The Graduate School of Life Science, Faculty of Advanced Life Science, Hokkaido University, Nishi 11, Kita 21, Kita-ku, Sapporo 001-0021, Japan.

Received: 26 July 2012 Accepted: 19 August 2012

Published: 31 August 2012

\section{References}

1. Futerman $A H$, Hannun YA: The complex life of simple sphingolipids. EMBO Rep 2004, 5:777-782.

2. Fahy E, Subramaniam S, Murphy RC, Nishijima M, Raetz CR, Shimizu T, Spener F, van Meer G, Wakelam MJ, Dennis EA: Update of the LIPID MAPS comprehensive classification system for lipids. J Lipid Res 2009, 50(Suppl):S9-14.

3. Masukawa Y, Narita H, Shimizu E, Kondo N, Sugai Y, Oba T, Homma R, Ishikawa J, Takagi Y, Kitahara T, Takema Y, Kita K: Characterization of overall ceramide species in human stratum corneum. J Lipid Res 2008, 49:1466-1476.

4. Ohnishi M, Fujino Y: Sphingolipids in immature and mature soy beans. Lipids 1982, 17:803-810.

5. Takakuwa N, Kinoshita M, Oda Y, Ohnishi M: Existence of cerebroside in Saccharomyces kluyveri and its related species. FEMS Yeast Res 2002, 2:533-538.

6. Takakuwa N, Tanji M, Oda Y, Ohnishi M: Distribution of 9-methyl sphingoid base in mushrooms and its effects on the fluidity of phospholipid liposomes. J Oleo Sci 2002, 51:741-747.

7. Mizutani Y, Mitsutake S, Tsuji K, Kihara A, Igarashi Y: Ceramide biosynthesis in keratinocyte and its role in skin function. Biochimie 2009, 91:784-790.

8. Imokawa G, Abe A, Jin K, Higaki Y, Kawashima M, Hidano A: Decreased level of ceramides in stratum corneum of atopic dermatitis: an etiologic factor in atopic dry skin? J Invest Dermatol 1991, 96:523-526.

9. Igarashi N, Okada T, Hayashi S, Fujita T, Jahangeer S, Nakamura S:
Sphingosine kinase 2 is a nuclear protein and inhibits DNA synthesis. J Biol Chem 2003, 278:46832-46839.

10. Uchiyama T, Nakano Y, Ueda O, Mori H, Nakashima M, Noda A, Ishizaki C, Mizoguchi M: Oral intake of glucosylceramide improves relatively higher level, of transepidermal water loss in mice and healthy human subjects. $J$ Health Sci 2008, 54:559-566.

11. Ishikawa J, Takada S, Hashizume K, Takagi Y, Hotta M, Masukawa Y, Kitahara T, Mizutani Y, Igarashi Y: Dietary glucosylceramide is absorbed into the lymph and increases levels of epidermal sphingolipids. J Dermatol Sci 2009, 56:220-222.

12. Gustafsson K, Sander B, Bielawski J, Hannun YA, Flygare J: Potentiation of cannabinoid-induced cytotoxicity in mantle cell lymphoma through modulation of ceramide metabolism. Mol Cancer Res 2009, 7:1086-1098.

13. Villani M, Subathra M, Im YB, Choi Y, Signorelli P, Del Poeta M, Luberto C: Sphingomyelin synthases regulate production of diacylglycerol at the Golgi. Biochem J 2008, 414:31-41

14. Taha TA, Osta W, Kozhaya L, Bielawski J, Johnson KR, Gillanders WE, Dbaibo GS, Hannun YA, Obeid LM: Down-regulation of sphingosine kinase-1 by DNA damage: dependence on proteases and p53. J Biol Chem 2004, 279:20546-20554.

15. Törmä H, Geijer S, Gester T, Alpholm K, Berne B, Lindberg M: Variations in the mRNA expression of inflammatory mediators, markers of differentiation and lipid-metabolizing enzymes caused by sodium lauryl sulphate in cultured human keratinocytes. Toxicol In Vitro 2006, 20: 472-479.

16. Zhao H, Miller M, Pfeiffer K, Buras JA, Stahl GL: Anoxia and reoxygenation of human endothelial cells decrease ceramide glucosyltransferase expression and activates caspases. FASEB J 2003, 17:723-724.

17. Karan G, Lillo C, Yang Z, Cameron DJ, Locke KG, Zhao Y, Thirumalaichary S, Li C, Birch DG, Vollmer-Snarr HR, Williams DS, Zhang K: Lipofuscin accumulation, abnormal electrophysiology, and photoreceptor degeneration in mutant ELOVL4 transgenic mice: a model for macular degeneration. Proc Natl Acad Sci USA 2005, 102:4164-4169.

18. Liton PB, Luna C, Challa P, Epstein DL, Gonzalez P: Genome-wide expression profile of human trabecular meshwork cultured cells, nonglaucomatous and primary open angle glaucoma tissue. Mol Vis 2006, 12:774-90.

19. Mandard S, Zandbergen F, Tan NS, Escher P, Patsouris D, Koenig W, Kleemann R, Bakker A, Veenman F, Wahli W, Müller M, Kersten S: The direct peroxisome proliferator-activated receptor target fasting-induced adipose factor (FIAF/PGAR/ANGPTL4) is present in blood plasma as a truncated protein that is increased by fenofibrate treatment. J Biol Chem 2004, 279:34411-34420.

20. Brown JM, Boysen MS, Jensen SS, Morrison RF, Storkson J, Lea-Currie R, Pariza M, Mandrup S, McIntosh MK: Isomer-specific regulation of metabolism and PPARgamma signaling by CLA in human preadipocytes. J Lipid Res 2003, 44:1287-1300.

21. Spinsanti G, Zannolli R, Panti C, Ceccarelli I, Marsili L, Bachiocco V, Frati F, Aloisi AM: Quantitative real-time PCR detection of TRPV1-4 gene expression in human leukocytes from healthy and hyposensitive subjects. Mol Pain 2008, 4:51.

22. Ponec $\mathrm{M}$, Weerheim $\mathrm{A}$ : Retinoids and lipid changes in keratinocytes. Methods Enzymol 1990, 190:30-41.

23. Farwick M, Lersch P, Santonnat B, Korevaar K, Rawlings AV: Developments in ceramide identification, synthesis, function and nomenclature. Cosmetics \& Toiletries 2009, 124:63-72.

24. Asai S, Miyachi H: Evaluation of skin-moisturizing effects of oral or percutaneous use of plant ceramides. Rinsho Byori 2007, 55:209-215.

25. Ueda O, Hasegawa M, Kitamura S: Distribution in skin of ceramide after oral administration to rats. Drug Metab Pharmacokinet 2009, 24:180-184.

26. Murakami I, Wakasa Y, Yamashita S, Kurihara T, Zama K, Kobayashi N, Mizutani $Y$, Mitsutake $S$, Shigyo T, Igarashi $Y$ : Phytoceramide and sphingoid bases derived from brewer's yeast Saccharomyces pastorianus activate peroxisome proliferator-activated receptors. Lipids Health Dis 2011, 10:150

27. Mao-Qiang M, Fowler AJ, Schmuth M, Lau P, Chang S, Brown BE, Moser AH, Michalik L, Desvergne B, Wahli W, Li M, Metzger D, Chambon PH, Elias PM, Feingold KR: Peroxisome-proliferator-activated receptor (PPAR)-gamma activation stimulates keratinocyte differentiation. J Invest Dermato/ 2004, 123:305-312. 
28. Sando GN, Howard EJ, Madison KC: Induction of ceramide glucosyltransferase activity in cultured human keratinocytes. Correlation with culture differentiation. J Biol Chem 1998, 271:22044-22051.

29. Mizutani Y, Kihara A, Igarashi Y: LASS3 (longevity assurance homologue 3) is a mainly testis-specific (dihydro)ceramide synthase with relatively broad substrate specificity. Biochem J 2006, 398:531-538.

30. Mizutani Y, Kihara A, Igarashi Y: Mammalian Lass6 and its related family members regulate synthesis of specific ceramides. Biochem J 2005, 390(Pt 1):263-271.

31. Ohno Y, Suto S, Yamanaka M, Mizutani $Y$, Mitsutake S, Igarashi $Y$, Sassa T, Kihara A: ELOVL1 production of C24 acyl-CoAs is linked to C24 sphingolipid synthesis. Proc Natl Acad Sci USA 2010, 107:18439-18444.

32. Kim S, Hong I, Hwang JS, Choi JK, Rho HS, Kim DH, Chang I, Lee SH, Lee $\mathrm{MO}$, Hwang JS: Phytosphingosine stimulates the differentiation of human keratinocytes and inhibits TPA-induced inflammatory epidermal hyperplasia in hairless mouse skin. Mol Med 2006, 12(1-3):17-24.

33. Sugawara T, Aida K, Duan J, Hirata T: Analysis of glucosylceramides from various sources by liquid chromatography-ion trap mass spectrometry. J Oleo Sci 2010, 59:387-394.

34. Hasegawa T, Shimada H, Uchiyama T, Ueda O, Nakashima M, Matsuoka Y Dietary glucosylceramide enhances cornified envelope formation via transglutaminase expression and involucrin production. Lipids 2011, 46:529-535.

35. Ideta R, Sakuta T, Nakano Y, Uchiyama T: Orally administered glucosylceramide improves the skin barrier function by upregulating genes associated with the tight junction and cornified envelope formation. Biosci Biotechnol Biochem 2011, 75:1516-1523.

doi:10.1186/1476-511X-11-108

Cite this article as: Shirakura et al:: 4,8-Sphingadienine and 4-hydroxy-8sphingenine activate ceramide production in the skin. Lipids in Health and Disease 2012 11:108.

\section{Submit your next manuscript to BioMed Central and take full advantage of:}

- Convenient online submission

- Thorough peer review

- No space constraints or color figure charges

- Immediate publication on acceptance

- Inclusion in PubMed, CAS, Scopus and Google Scholar

- Research which is freely available for redistribution 